\title{
Espaço, profissão e gênero: mobilidade e carreira entre juízes e juízas no Estado de São Paulo*
}

Gessé Marques Jr.**

\section{Resumo}

Por meio de pesquisa realizada com juízes e juízas no estado de São Paulo, este artigo revela que, apesar de um discurso interno $e$ de diretivas institucionais igualitárias, a carreira desses profissionais é marcada por diferenças e desigualdades de gênero. Este trabalho faz uma interconexão entre gênero, profissão $e$ espaço, e mostra como a construção das carreiras dos juízes(as) analisados está relacionada com a capacidade individual de mobilidade e deslocamento espacial no estado.

Palavras-chave: Profissão, Profissão Jurídica, Juízes, Espaço, Gênero.

* Recebido para publicação em 27 de outubro de 2011, aceito em 7 de agosto de 2014.

** Professor na Faculdade de Ciências Humanas, na Universidade Metodista de Piracicaba.gessemqs@gmail.com 
266 Espaço, profissão e gênero

Space, Profession and Gender: Mobility, Career and Judges in the State of São Paulo

\begin{abstract}
By means of a survey of male and female judges in the state of São Paulo, this article reveals that, despite purportedly egalitarian discourse, the judicial profession is marked by gender differences and inequalities. Here, we make interconnections between gender, profession and space. Furthermore, we describe how the building of the careers of the surveyed subjects depends upon individual ability for mobility and spatial dislocation across the state.
\end{abstract}

Key Words: Profession, Legal Profession, Judges, Space, Gender. 


\section{Introdução}

Embora os discursos recorrentes entre juízes e juízas no estado de São Paulo afirmem a não discriminação e a igualdade de gênero, assim como padrões profissionais e juridicamente formais entendidos como objetivos e não discriminatórios na construção e na ascensão da carreira jurídica, neste artigo procuramos demonstrar que diferenças de gênero estabelecem capacidades diferenciadas de mobilidade pelo território, e que as possibilidades de mudança e deslocamento espacial são determinantes na construção de habilidades pessoais, carreiras $e$ hierarquia na magistratura.

Inicialmente, o artigo analisa a literatura referente a gênero $e$ trabalho jurídico; apresenta o campo e metodologia de pesquisa; expõe os requisitos para a entrada e a progressão na carreira jurídica. Com dados de entrevistas, mostra as diferentes formas de apropriação da profissão e demonstra como as possibilidades de deslocamento e mudança entre cidades e comarcas pelo estado são fundamentais na carreira, sendo determinantes na produção de diferenças de gênero.

Partindo dos casos analisados para um entendimento teórico mais abrangente, o trabalho permite estabelecer interconexões causais entre mobilidade espacial, progressão na profissão e diferença de gênero, afirmando, desse modo, a importância dos deslocamentos espaciais na construção diferencial das carreiras profissionais.

Este artigo é parte da pesquisa "Profissionalismo e gênero nas carreiras jurídicas", coordenada por Maria da Gloria Bonelli e financiada pelo CNPq, entre 2010-2011 (Bonelli, 2011). Apresentaremos um desenvolvimento do relatório individual inicial, fruto da participação no processo de coleta de dados, pesquisa de campo e discussões entre os membros do grupo.

Os dados apresentados neste trabalho foram coletados por meio de entrevistas com roteiro semiestruturado aplicadas por seis pesquisadores em Fóruns do Tribunal de Justiça de São Paulo (TJSP) e do Tribunal Regional Federal, $3^{\text {a }}$ região (TRF-3), tanto na 
capital como em cidades do interior do estado. Devido aos limites jurídicos presentes no "Termo de consentimento livre $e$ esclarecido", as cidades e os profissionais não serão nomeados, resguardando o sigilo e a confidencialidade.

Foram realizadas 28 entrevistas, 14 com juízes e juízas estaduais, quatro com desembargadores(as) estaduais, e $10 \mathrm{com}$ juízes(as) federais. Do total de magistrados(as), nove atuavam na capital e 19 em cidades do interior do estado; 57\% são mulheres, sendo uma desembargadora, nove juízas estaduais e seis juízas federais. Há uma variação na faixa etária, com a maioria entre 35 e 49 anos (50\%). Até 34 anos, há $21 \%$ e a partir de 50 anos, 29\%. Nesta última faixa, apenas um deles era juiz federal, sendo os demais entrevistados do TJSP (Bonelli, 2001).

Embora houvesse a preocupação em selecionar profissionais em diferentes momentos da carreira, oito dos entrevistados atuavam em comarcas de entrância final e quatro em entrância intermediária. Desses 14 juízes e juízas estaduais, 10 eram juízes(as) titulares atuando em suas varas, três titulares auxiliares atuando em varas de outros juízes e um substituto; além dos quatro desembargadores da segunda instância. A nossa amostra é restrita em termos de localidades, progressão na carreira e a não presença de juízes em entrância inicial. Na TRF-3, seis eram juízes titulares e quatro substitutos. As entrevistas em profundidade permitiram um amplo conhecimento, ainda que a amostra estatística seja reduzida frente à totalidade dos juízes(as) no estado de São Paulo.

\section{Gênero, trabalho jurídico, advogados(as)}

Em termos de problemática de gênero e trabalho, podemos perceber que a participação feminina no total de portadores de título superior tem aumentado nas últimas décadas, ultrapassando o contingente masculino. Em 2003, dos 528.223 concluintes do terceiro grau no Brasil, 329.311 eram mulheres (62\%) (Brasil, INEP, 2007). A Pesquisa Nacional por Amostragem de Domicílios PNAD 2005 encontrou 7.714.890 mulheres com ensino superior; 
para os homens esse número foi de 6.058 .704 (56\% a 44\%) (PNAD, 2005). Em decorrência, há crescimento da presença delas no mercado de trabalho profissional, especialmente nas carreiras identificadas como guetos femininos, voltados para os cuidados, artes e humanidades (Bruschini; Lombardi, 2000).

A advocacia também registra um aumento de mulheres. A OAB nacional, em 2006, tinha 312.734 advogados e 248.085 advogadas (56\% a 44\%); a OAB-SP contava com 116.948 homens e 93.245 mulheres (56\% a $44 \%$ ), sendo que nos últimos três anos o número de novas inscritas superou os novos inscritos, com 35.873 advogadas e 32.763 advogados (52\% a 48\%) (Barbalho, 2008).

Em paralelo à ampliação da participação feminina nas carreiras jurídicas, na advocacia os conflitos profissionais decorrentes da intensificação da divisão social do trabalho foram nuançados pela divisão sexual do trabalho, com as mulheres concentrando-se nas áreas tradicionais e nas atividades mais rotineiras $e$ os homens naquelas mais novas e especializadas (Bonelli et al., 2008).

Investigando semelhanças e diferenças de gênero em 216 profissionais em São Paulo, as autoras afirmam que o discurso feminino promove o apagamento das diferenças $e$ da discriminação de gênero, apoiando-se na neutralidade da expertise, para a qual o que importa é demonstrar competência. É a luta para provar a capacidade, que permanecerá indissociável da dedicação full-time e da interminável administração do tempo (Bonelli et al., 2008:268).

Dados de pesquisa na França definem um script sexuado orientando o trabalho, pois a conciliação com a vida familiar $e$ profissional é atribuição exclusivamente feminina $e$ a pressuposição da competência na esfera profissional é monopolizada pelos homens. A indisponibilidade masculina na esfera doméstica combina-se com a "escolha" das mulheres por trabalhos que permitem usufruir de soberania sobre seu tempo, $e$ exercê-lo em locais menos hostis, o que explicaria em parte, a subrepresentação feminina nas posições privilegiadas no mercado 
profissional, fator que incide sobre a remuneração obtida (Feuvre; Lapeyere, 2005:113-122).

Embora haja um aumento de mulheres nas profissões jurídicas na Inglaterra, Bolton e Muzio (2007:50-62) demonstram que as mulheres estão ausentes dos escritórios mais prestigiosos, das áreas mais lucrativas, e sedimentam suas atividades em áreas específicas de atuação jurídica. Os autores revelam mecanismos internos de fechamento de gênero e de discriminação na profissão distribuídos das seguintes formas: em termos de estratificação salarial, há impedimento de ascensão às posições sênior $e$ a discriminação se fundamenta em "ideologia de envolvimento" $e$ necessidade de dedicação total ao trabalho, como afirmamos sobre o full-time. De modo horizontal, há segmentação de papéis ocupacionais e o confinamento em áreas menos prestigiosas $e$ com menores rendimentos, tais como Direito de Família e do Trabalho, que também aparecem no trabalho de Bonelli et. al. (2008) e de Pierce (1995). Finalmente, afirmam uma sedimentação, pois a estratificação e a segregação são perpetuadas e a mulher se organiza dentro desses "enclaves", mantendo o ciclo com a construção de atributos profissionais como se fossem típicos femininos.

Em pesquisa realizada em escritórios de advocacia em Toronto, Canadá, com o objetivo de avaliar e relacionar satisfação e insatisfação no trabalho com gênero, Hagan \& Kay (2007) afirmam que as mulheres tendem a privatizar os sentimentos de insatisfação e hostilidade enquanto os homens tendem a torná-los públicos. Com ampla análise de dados estatísticos, os autores verificaram que apesar de ganharem menores salários e de estarem mais sujeitas a mudanças de emprego, as mulheres apresentam um índice de satisfação com o trabalho similar ao dos homens. Os autores acreditam que isso ocorre porque externalizar as insatisfações não teria um valor tão forte para as mulheres quanto há para os homens. Mas, ao analisar as fontes de insatisfação, preocupação e melancolia que afirmam recorrentes, mostram como as preocupações no cuidado e com o tempo com os filhos são fatores preponderantes, assim como os filhos são 
qualificados como impedimentos para a ascensão e a participação na sociedade dos escritórios.

Entre advogados em São Paulo constatou-se carga horária equivalente, mas não remuneração igual entre homens $e$ mulheres. As mulheres concentram-se em posições menos privilegiadas nas hierarquias dos escritórios e, embora tenham formação e capital acadêmico semelhantes, os homens têm maiores possibilidades de continuidade de formação devido à sociabilidade em redes $e$ às práticas que consolidam os vínculos de masculinidade. As mulheres predominam nos escritórios de médio porte, em posições subordinadas, mais direcionadas para a área de Direito de Trabalho, com um "gueto feminino" em Direito de Família. Os homens vão para o contencioso, para o Direito Societário, Direito Comercial, Penal, Civil, Tributário, Administrativo (Bonelli et al., 2008:275-278). Essas diferentes escolhas profissionais levam a diferentes possibilidades de salário $e$ prestígio profissional. Os dados de Inglaterra, Canadá e Brasil repetem as diferenças entre as atividades direcionadas ao cuidado $e$ à família - entre as mulheres -, em oposição às áreas mais prestigiosas, com caráter mais público e maior rendimento salarial, entre os homens.

Essas referências mostram crescentes envolvimento $e$ participação das mulheres na advocacia $e$ trazem dados $e$ diretrizes teóricas que permitem analisar e os contrapor aos processos de discriminação e desigualdade de gênero que encontramos na pesquisa realizada entre juízes(as).

Nesse sentido, entendemos gênero como uma categoria relacional, envolvida em conflitos de poder (Scott, 1990), que não pode ser submetida a análises a-históricas (Corrêa, 1999) de dominação masculina essencializada, tal como aparece na obra de Bourdieu (2002), e nem pode ser totalizada ou resumida por uma categoria de identidade descritiva, mas é um termo em permanente abertura e ressignificação (Butler, 1998:36), que envolve diferenciações e discriminações alocadas em sexo. 


\section{Formação jurídica e diferença profissional: $\operatorname{advogados(as)~e~}$ juízes(as)}

Embora a formação acadêmica seja comum e o quadro teórico e epistemológico similar a orientar as ações profissionais, a construção da carreira pública do magistrado é bem diferente da de advogados que atuam na esfera privada.

$\mathrm{Na}$ magistratura, a entrada na carreira é por concurso público, com critérios objetivos de seleção na prova escrita, e critérios mais subjetivos na prova oral e na entrevista.

Embora as desigualdades e formas de discriminação de gênero estejam presentes nos discursos dos juízes(as) entrevistados, de modo geral são localizadas num passado dito remoto. Surgem histórias e situações - "um animal que sangra quatro dias e não morre, não tem condições de julgar"-, em que discursos públicos de desembargadores rejeitavam ostensivamente a presença de mulheres. E, ainda que recorrentes, os exemplos do passado se defrontam com afirmações de que hoje não é mais assim.

Bonelli (2011) sistematiza as respostas sobre desigualdade do seguinte modo:

As temáticas de gênero, diversidade e preconceito foram as que reuniram mais manifestações de opinião dos entrevistados: $85 \%$ deles negaram que o gênero fosse um fator que gerasse diferenças nas oportunidades de carreira na instituição, mas $75 \%$ identificaram que ele fazia diferença no exercício da judicatura. ${ }^{1}$ As juízas do TRF-3 foram unânimes em afirmar que na magistratura o gênero não era um fator de desigualdade.

Como afirmado anteriormente, na advocacia há um discurso de apagamento das diferenças e desigualdades de gênero que caminha ao lado de formas de estratificação e segmentação

\footnotetext{
1 Embora haja um discurso recorrente entre juízes(as) afirmando diferenças de gênero nos julgamentos, nas decisões judiciais, não analisaremos essa problemática neste trabalho.
} 
nas diferentes áreas de atuação de acordo com gênero. Embora juízes(as) e advogados(as) tenham uma formação acadêmica comum, na magistratura a escolha das Varas Especializadas e a segmentação profissional dependem da oferta de vagas nos concursos internos e não de uma diretriz de gênero. Assim, um direcionamento ou a criação da aptidão baseada em gênero Direito de Família ou Empresarial - não ocorre para os juízes(as). Entre eles as possibilidades de atuação nos diferentes ramos do direito estão relacionadas à constante oferta de vagas oferecidas no estado.

Neste sentido, Bonelli (2011:12-13) afirma que:

Quanto à área e atuação, não observamos uma concentração por gênero em nenhuma área específica, havendo equilibrio na amostra entre direito público $e$ privado, entre cível e criminal. As varas de família e as de infância $e$ juventude, que poderiam ser associadas aos cuidados, também não formam guetos femininos, e na amostra da pesquisa, os dois juízes estaduais que atuam em varas de família são homens. O mesmo se verifica para a posição de juiz auxiliar em varas que possuem juiz titular $e$ para os juizados especiais, que lidam com as "pequenas causas". Não foram observadas segmentações $e$ sedimentações no TJSP ou no TRF-3. Neste último tribunal, há uma proporção semelhante de homens e mulheres como juiz substituto, que é o início da carreira. Nos juizados especiais federais do Estado de São Paulo, há 58\% de mulheres para $42 \%$ de homens. Nos juizados especiais da justiça estadual há $60 \%$ de homens $40 \%$ de mulheres. (Dados coletados nos sites do TJSP e do TRF-3, em 24-2-2011).

A partir desses dados, podemos perceber que as formas de segmentação, estratificação e sedimentação relacionadas a especialidades que ocorrem entre os advogados(as) não se repetem na magistratura, reforçando a noção de identidade relacional e situacional (Strathern, 2006; Costa, 1998). E nesse sentido, a construção da carreira ocorre para além de uma 
naturalização de desejos, habilidades, aptidões e opções de gênero nas profissões.

Como há uma mudança na estrutura, na forma, no modelo de construção de carreira profissional, também vemos novas formas de identidade profissional.

Assim, entre os advogados(as) ocorre um processo crescente de elaboração de aptidão e especialização relacionados com gênero. Além disto, a composição da carteira de clientes, de contatos e conhecimentos pessoais e profissionais exigidos pelas profissóes liberais, exigem o fortalecimento e o desenvolvimento de raízes num território fixo e sedentário.

$\mathrm{Na}$ magistratura, a escolha da vara $e$ a possibilidade de especialização em algum dos ramos do direito dependem da mobilidade pelo território, seja no estado de São Paulo - TJSP, ou em São Paulo e Mato Grosso do Sul, TRF-3. Veremos que, na magistratura, as variáveis de gênero interagem com o contexto $e$ a capacidade de deslocamento espacial entre varas e comarcas, $e$ portanto, não se formam "nichos" femininos ou masculinos de atuação.

\section{Antiguidade, território e a progressão na carreira}

No início de nossas entrevistas, o Juiz $27^{2}$ questionou, duvidou e levantou problemas para os propósitos e objetivos da pesquisa que iniciávamos, afirmando categoricamente a não existência de diferenças de gênero.

Profissionalmente não há diferença de gênero. A carreira da magistratura basicamente segue a antiguidade. A magistratura tem se pautado pelo respeito à antiguidade. $\mathrm{E}$ quando $o$ magistrado alcança a antiguidade é automaticamente promovido. Não há qualquer forma de preterimento (Juiz 27, estadual, 41 anos, casado com juíza, com filhos).

2 Colocamos números para diferenciar os juízes(as) e facilitar as remissões e referências cruzadas que faremos no desenvolvimento do texto. 
O critério de antiguidade é a premissa que orienta suas afirmações. Assim, se a partir da entrada na carreira os diferentes juízes(as) atuarem dentro das expectativas e critérios profissionais estabelecidos - não sofrendo graves repreensões, atendendo as correições do TJSP e mantendo os processos e decisões "em dia", eles estarão sujeitos ao critério institucional igualitário, objetivo $e$ formal, de progressão pelo tempo de serviço.

Devido à antiguidade estariam imunes a preconceitos $e$ diferenças de gênero $e$ alcançariam os diferentes patamares hierárquicos, cujo ápice - nessa magistratura estadual - é tornar-se desembargador(a) da segunda instância no Tribunal de Justiça na cidade de São Paulo.

Embora, como veremos adiante, existam juízes(as) que não compartilham e que se afastem desse objetivo, chegar à segunda instância se apresenta como meta impositiva e dominante entre esses profissionais, sendo $\mathrm{o}$ ideal de profissão social $e$ institucionalmente reconhecido e valorizado na magistratura.

Para chegar a esse local/hierarquia é necessária uma série de cálculos e conjunturas institucionais em um percurso com tempo/espaços determinados, pois a carreira encerra-se aos 70 anos de idade com a aposentadoria compulsória. Assim, dependendo da idade de ingresso na carreira, da quantidade e da abertura de vagas oferecidas no período, esses profissionais podem fazer cálculos quanto à possibilidade de "correr na carreira" e alcançar a segunda instância.

O cálculo - sem pensar nas alianças e conflitos políticos, que não iremos analisar neste trabalho - depende da idade de início na magistratura, das oportunidades de mudança entre entrâncias e da própria configuração da carreira.

Existem momentos em que a carreira "anda" e outros em que fica "parada". Quando, por exemplo, há um grande número de aposentadorias, abrem-se novas vagas $e$ as promoções $e$ o deslocamento entre as varas ocorrem consecutivamente. Todavia, quando os cargos estão ocupados toda a sequência fica paralisada. Ou seja, em alguns períodos a carreira tem grande mobilidade, e em outros fica estacionada. Dependendo do 
momento em que os juízes(as) entraram, do cálculo da idade e do tempo de permanência nas diferentes entrâncias, calcula-se se terão condições de chegar a segunda instância ou não.

De acordo com Bonelli (2011: 29)

a primeira instância do TJSP está dividida em quatro degraus que permitem o acesso à segunda instância: o juiz ou juíza toma posse como substituto, depois, por meio das promoções organizadas pelo Tribunal de Justiça, torna-se Titular na entrância inicial, na entrância intermediária e na entrância final.

A primeira instância é formada por juízes singulares que atuam em diferentes varas e comarcas do estado. As varas podem ser especializadas em Direito de Família, Direito Civil, Criminal, Infância e Adolescência, etc.; ou podem ser acumulativas. As varas acumulativas - chamadas de "Clínica Geral" - reúnem, às vezes, todos os ramos do direito numa única comarca (geralmente em cidades menores, onde pode haver somente uma ou duas varas). Essas varas são mais frequentes nas entrâncias iniciais, exigindo que os juízes(as) em começo de carreira respondam a todos os ramos do direito. ${ }^{3}$

\section{Início da carreira}

Ao passar no concurso no TJSP, o juiz ou juíza toma posse como Juiz Substituto(a) e, dependendo de sua classificação, escolhe a circunscrição onde trabalhar. A circunscrição é uma delimitação territorial que abrange diferentes cidades em determinadas e diferentes regiões do estado de São Paulo.

Ao descrever o concurso Bonelli (2011:29) afirma que:

3 Neste trabalho não analisaremos as dificuldades encontradas pelos juízes(as) novatos frente à imposição de um conhecimento de todos os ramos do direito no início da carreira, nem a distribuição espacial dos "novatos" entre as varas menos prestigiosas do estado. 
Antes de 1996, os candidatos eram identificados pelo nome nos exames, observando-se então uma alta eliminação de nomes femininos. A partir daí, os exames escritos passaram a omitir essa identificação, registrando os candidatos por números de inscrição e a aprovação feminina nessa etapa cresceu. Atualmente, chega ao exame público oral uma proporção maior de mulheres do que de homens, havendo na mesma ocasião uma entrevista com a banca, etapa na qual a vantagem feminina desaparece. Avaliações subjetivas e pouco transparentes sobre a postura profissional desejada seguem existindo e controlando o ingresso na carreira. Este controle é interno, feito pelos desembargadores, os pares profissionais do topo da hierarquia judiciária, onde a predominância masculina permanece impressionante.

Seguindo essa análise, embora haja um maior número de mulheres aprovadas nos concursos, a classificação final pode exprimir orientação de gênero. Em termos de distribuição espacial, como a escolha e a definição de vagas dependem da classificação, os melhores colocados irão para os lugares que entendem como ideais de localização, de residência definitiva, de proximidade com a cidade de São Paulo, ou da estratégia particular de localização e mobilidade espacial para "correr na carreira".

O Tribunal de Justiça é o órgão máximo da administração da justiça estadual e nele são elaboradas as diretrizes da profissão: a distribuição de poder; as formas de seleção e classificação nos concursos; os critérios para a abertura de vagas e a movimentação dos juízes entre as diferentes varas, seja por remoção ou por progressão; a proximidade com os desembargadores, que indicam cargos de administração, cargos de auxiliares nos votos da segunda instância, ou de assessoria da presidência.

Além do vetor de progressão na carreira (de substituto até titular em entrância final), a posição relativa das comarcas em relação à capital define posições diferenciadas na hierarquia de poder. Para aqueles que desejam progredir e ocupar lugares de poder, além de percorrerem as diferentes entrâncias também é 
necessário o deslocamento do interior para a capital (vetor de poder/espaço: do interior para a capital). Ainda que um juiz residente, por exemplo, na entrância final de Presidente Prudente (563 km de distância da capital) esteja no mesmo patamar hierárquico que um juiz nas entrâncias finais de Campinas (101 km), Santos (79 km), São José dos Campos (104km) ou São Paulo, ele não poderá participar do cotidiano de atividades do Tribunal, nem da rede de relações pessoais-profissionais que permite a ocupação de cargos de confiança e rendimentos extras.

"Correr na carreira" exige a administração da progressão/hierarquia e do tempo (período) nas entrâncias que não pode ser dissociada do deslocamento espacial pelo território. Se para os advogados(as) o sedentarismo/profissão liberal/opção de ramos do direito é determinante na construção da carreira, para os juízes(as) o que importa é a hierarquia e a capacidade de mobilidade espacial pelo território do estado.

\section{De substituto a titular: a mobilidade pelo estado de São Paulo}

Como afirmamos acima, existem duas variáveis determinantes e inter-relacionadas na composição das carreiras profissionais dos juízes(as). Em primeiro lugar, para progredir é necessário "estar disposto(a)" às mudanças, à mobilidade e à trajetória espacial dentro do estado de São Paulo. Em segundo lugar, o gênero é fundamental nesses deslocamentos e na progressão espaço/territorial/hierárquica da carreira.

Em termos de espaço e mobilidade - ou de restrição de mobilidade -, enquanto são substitutos, os juízes(as) ficam dependentes das decisões do Tribunal de Justiça, que indica os lugares onde vão atuar, pois ainda não adquiriram as garantias constitucionais da inamovibilidade. Por isso, podem circular entre diferentes varas numa circunscrição ou serem mandados para outra circunscrição, de modo a atender as necessidades do Tribunal. 
Eu fui substituta em Marília porque foi o que sobrou para mim. [...] Daí eu fui para Marília, mas não ficava só em Marília, ficava num monte de lugares, então fui para as mais diversas Comarcas. Naquela época, substituto rodava quilômetros. Para você ter uma ideia, eu comprei um carro no meio do ano, em março, abril, daí eu troquei o carro de novo em dezembro, ele estava com sessenta mil quilômetros, então assim rodava bastante, de Marília eu me removi para Bragança, mas continuei rodando bastante.

- Mais isto como substituta ainda? (pesquisador)

Como substituta. Eu fui para lepê que é perto de Presidente Prudente, comarquinha minúscula; é uma vara distrital, distrital de lepê.

- Mas aí substituta também?

Nessa titular. Nessa eu fiquei dois meses só, eu fiz carreira rápido, depois de lá eu fui para,

- O que é fazer carreira? O que vocês, quando falam fazer carreira rápida, o que isso quer dizer?

É assim, a promoção do juiz ela se dá, o juiz tem na mobilidade... Então você toma posse como substituto de determinada comarca, isso é feito assim: tem vaga em tal, tal, tal comarca e conforme a sua classificação no concurso você vai ser o primeiro, segundo terceiro a escolher; e vai escolhendo o que sobra. Para mim, sobrou Marília na época. Depois você tem uma inamovibilidade; se eu quisesse ser o resto da vida substituta em Marília eu não sou obrigada a me promover, eu seria substituta em Marilia o resto da vida (Juíza 4, estadual, 39 anos, casada com médico, com filhos).

Nessa entrevista verificamos que o concurso é determinante na primeira escolha da comarca ou, de acordo com a sua classificação, na sina de escolher o que sobrar. Segundo, há uma instabilidade e mobilidade "forçada" impostas ao substituto. Terceiro, é necessário rapidamente tornar-se juiz titular em entrância inicial - ainda que distante da residência desejada - se o objetivo for "correr na carreira", assim como há a possibilidade de 
se estabelecer no interior e não se promover; retardando ou abrindo mão da progressão na carreira.

Traduzindo a trajetória/carreira dessa juíza pelo estado de São Paulo em um mapa ${ }^{4}$, vemos o longo caminho percorrido até chegar a Campinas, sua cidade natal e residência da família/marido, e objetivo definido desde o início do seu percurso.

\section{Mapa da Juíza 4}

Segundo a Juíza 4, o fato de o marido ser médico com clínica estabelecida em Campinas impossibilitou que ele a acompanhasse em sua peregrinação pelo Estado de São Paulo. Quando solteira iniciou como juíza substituta em Marília (A) e foi designada para trabalhar em diversas cidades daquela região. Ainda substituta, foi para Bragança Paulista (B); foi promovida e tornou-se titular em Iepê, entrância inicial (C). Foi promovida para entrância intermediária em Barra Bonita (D) e, casada e com filho, chegou à entrância final em Taubaté (E). Depois de trabalhar durante 4 anos em Taubaté, conseguiu uma permuta e mudou-se para Campinas. Dos 15 anos como juíza, se estabeleceu definitivamente em Campinas nos últimos quatro, ou seja, precisou de 11 anos de transferências e deslocamentos até chegar ao local que imaginava como ideal para suas profissão/residência/família.

4 Os mapas foram elaborados pelo Google Mapas. Disponível em: http://maps.google.com.br/maps. 


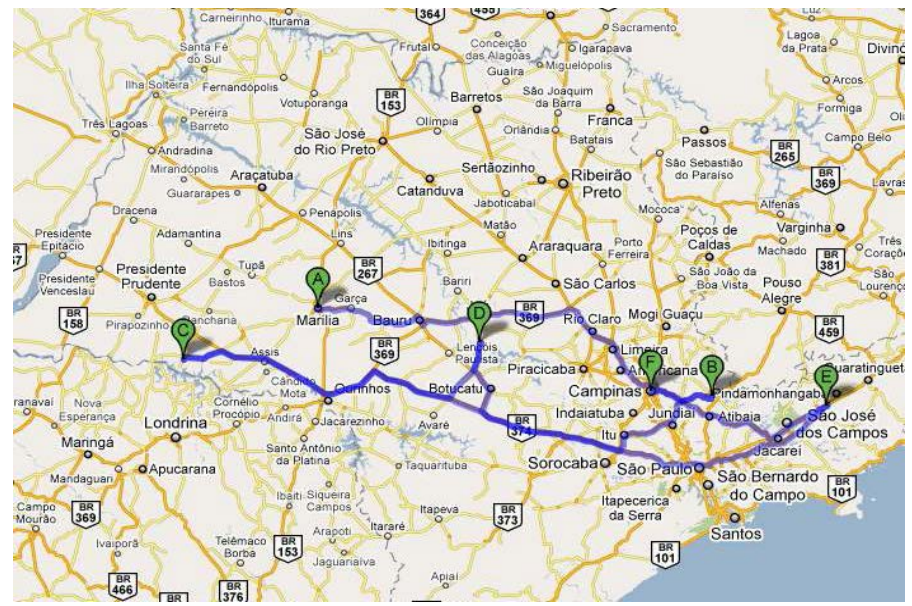

Assim como no TJSP, no TRF-3 a mobilidade é fundamental na construção da carreira. A escolha inicial como juiz substituto depende da classificação no concurso, e a partir de uma lista de antiguidade o profissional terá preferência para escolher a vara onde será titular. Similar ao TJSP, as vagas são criadas conforme ocorrem as aposentadorias ou pela criação de novas varas. Os juízes não são obrigados a progredir na carreira e podem esperar por vagas mais adequadas aos seus projetos de vida. Diferente do TJSP, o TRF-3 inclui o estado de Mato Grosso do Sul, o que pode levar os juízes(as) a percorrerem maiores distâncias.

\section{Mapa da Juíza 22.}

Juíza 22 (federal, 35 anos, casada com funcionário da Justiça Federal, dois filhos). Natural de Jaú, entrou na magistratura em 1999 e iniciou como substituta em Araçatuba e cidades vizinhas; as vagas disponíveis estavam a mais de $500 \mathrm{~km}$ de São Paulo. Nessa fase tinha duas casas: uma em Araçatuba e outra em São Paulo(A) onde morava seu marido. Progrediu para titular em Junqueirópolis durante seis meses (B), passou por Igarapava (C), Monte Alto (D), Barra Bonita (E) e, finalmente, Jaú (F). 


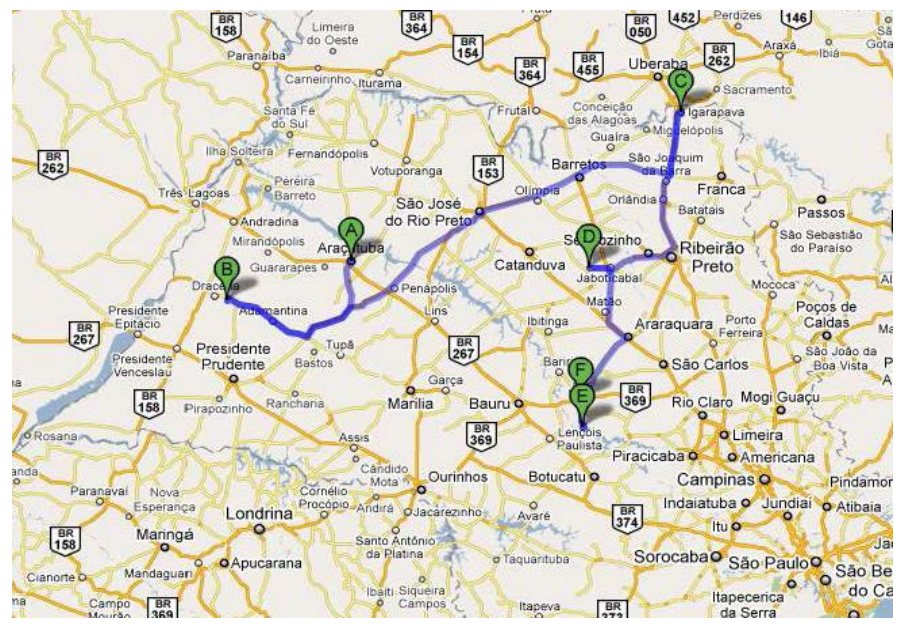

Ao justificar suas escolhas de localidade, ela apresenta outros dados relativos a mobilidade espacial e carreira. Ficar no interior pode ser entendido como opção pessoal e posicionamento frente ao poder e à carreira, diferenciando aqueles que se deslocam para São Paulo daqueles que ficam no interior.

Eu tenho colegas que ingressaram junto comigo na carreira e que estão em cargos de comarcas menores, do mesmo jeito que eu tenho colegas que estão em cargos de cidades maiores, mas tudo de acordo com as expectativas pessoais. Eu preferi, eu poderia em 2003... ter ido para uma cidade maior na Grande São Paulo, mas por uma questão pessoal eu preferi permanecer no interior, porque eu e o meu marido entendemos juntos que, tanto para mim como para ele, seria melhor para nós criarmos nossos filhos no interior. Como a carreira conforme ela se desenvolve você acaba se direcionando para São Paulo, que é o centro do estado, que é o centro político do estado, eu teria que ir para São Paulo para, digamos assim, progredir na carreira, e nós entendemos que por questões pessoais nossas, nós deveríamos permanecer aqui. Agora, tenho colegas que buscaram esse progresso profissional e estão na cidade de São Paulo e estão mais próximas de alcançar cargos de níveis superiores na carreira, muito mais cedo do que eu. 
Embora tenha elaborado mapas de duas juízas, a necessidades $e$ as histórias de mobilidade e trajetória pelo território estão presentes nos relatos de todos os entrevistados, e se relacionam com a progressão na carreira, vínculos familiares, limites e possibilidades de envolvimento na política e nas formas de poder que envolvem a profissão.

Nas duas entrevistas, vemos uma relação de conflito e para a construção de carreira profissional é preciso conciliar os desejos $e$ as expectativas da profissão com os limites da vida familiar, casamento e criação de filhos. O desenvolvimento profissional das duas juízas mostra as ambiguidades entre família e profissão. A Juíza 4 se deslocou por diferentes cidades enquanto seu marido médico/profissional liberal não deixou a localidade de origem $e$ em alguns momentos da entrevista disse das dificuldades que isso implicava para a maternidade e a criação dos filhos. Mesmo assim, a Juíza 4 corre na carreira, está em última entrância e apta a concorrência para segunda instância. A Juíza 22 faz a opção pelos filhos, família e por um sentido de criação de vida no interior, $e$, diferentemente da Juíza 4, abre mão de uma inserção mais competitiva na carreira, estabelecendo-se no interior do estado.

Apesar das diferenças, os dois casos mostram as dificuldades de conciliar profissão, família e deslocamento pelas fronteiras espaciais que demarcam as expectativas e pressões do grupo por ascensão, ou que justificam as paradas e hesitações nas bordas do devir desembargador.

\section{Antiguidade relativa: disputa por varas, hierarquia nas entrâncias, mobilidade e gênero}

Os juízes(as) tomam posse como substitutos e, dependendo de sua classificação no concurso, podem residir distantes da capital. Como mostramos no primeiro mapa, a Juíza 4 inicia sua carreira como substituta em Marilia, aproxima-se de Campinas ao se remover para Bragança Paulista, mas progride para Titular em lepê (518 km da capital), "correndo na carreira", como ela disse. 
Como o critério antiguidade determina a ocupação das diferentes varas, as entrâncias iniciais mais próximas da capital são as mais cobiçadas e tornam-se difíceis para o juiz substituto em início de carreira.

Isso ocorre porque há duas formas de concurso interno para ocupação de vagas: por "remoção" ou por "progressão". A remoção entre as entrâncias - "deslocamento lateral" ou "progressão lateral" - tem prioridade e permite que os titulares "circulem" em busca das melhores comarcas. Também baseado na antiguidade, e após as remoções, há concurso para progressão. É nesse momento que o substituto pode concorrer e tornar-se titular, ou que os titulares progridem da entrância inicial para a intermediária e dela para a final, e, finalmente, para a segunda instância. Por isso, se quiser "correr na carreira" e tornar-se rapidamente um juiz titular, o substituto irá às comarcas menos concorridas e distantes da capital, tornando-se apto a concorrer por varas mais cobiçadas, ou "de volta para casa", ou rumo à capital.

Como uma das variáveis da concorrência é determinada pela classificação no concurso, se seguirmos a análise de Bonelli, o gênero será determinante no local de trabalho, e, assim, podemos questionar a igualdade de gênero pela formalidade da antiguidade e salientar sua importância e suas possibilidades na mobilidade $e$ nos deslocamentos pelo espaço.

A partir dos depoimentos dos juízes(as), relativizaremos a questão da antiguidade e competência dentro da carreira $e$ passaremos a pensar a ascensão profissional na relação entre espaço e gênero; iniciando com a análise do Desembargador 2.

Segundo ele, a maternidade, a família e os filhos são impedimentos que atingem, especialmente, a carreira das mulheres.

$\mathrm{O}$ que a gente verifica, às vezes, na maternidade, o que acontece, é que prende a juíza numa determinada comarca. Então, por exemplo, ela é juíza lá em Santos, então os filhos adaptados lá, tudo mais... Hoje Santos é entrância final. Vamos pegar comarquinha. Por exemplo, tem uma colega que está lá em Socorro, ela está lá adaptada com os filhos pequenos, o que ela quer fazer? Ela fica com a carreira 
limitada porque ela quer sair de lá pra ir pra uma comarca perto. Então a promoção dela fica limitada, isso faz com que outros colegas homens e mulheres, que não têm essa limitação, passem na frente dela (64 anos, casado, 3 filhos. Desembargador desde 2004).

Essa entrevista apresenta problemas de gênero, pois embora vínculos familiares não sejam uma limitação profissional exclusiva às mulheres, as responsabilidades de cuidado e de restrição de mobilidade são orientadas preferencialmente para as mulheres casadas e/ou com filhos.

Juíza 3 (estadual, auxiliar em entrância intermediária, 30 anos, casada com Juiz 9, 39 anos, com filhos) também estabelece diferenças em relação aos homens. Com filhos ainda pequenos, explica suas opções como construção de lugar em oposição ao deslocamento espacial e carreira. Se a carreira não se define por ramos do direito voltados ao cuidado [como dissemos dos advogados(as) e outras profissões (Bruschini; Lombardi, 2000)], as atividades de cuidado orientam a apropriação e fornecem sentido ao território e à carreira na magistratura.

[...] Acho que não, acho que a mulher não entra na magistratura... por exemplo, é difícil você ver uma mulher que pensa em fazer carreira, em querer chegar a ser desembargador, ela quer achar um lugar. Eu vejo pelas auxiliares mesmo, elas querem achar um lugar próximo ao lugar em que moram. Geralmente, as mulheres ficam mais tempo para se promoverem justamente porque esperam um lugar melhor, próximo ao local do marido se for casada. Acho que a tentativa de conjugação trabalho e família é maior em relação às mulheres do que aos homens, até mesmo porque é difícil você ver um homem que vai atrás da mulher (Juíza 3).

Ao explicar sua trajetória na carreira e como deixou de ser substituta, a juíza revela como esse processo envolve deslocamento espacial e, por não tê-lo feito, analisa sua posição: 
[...] se pensa na carreira como substituto... você só se promove para uma inicial, essas comarcas pequenas, quando você se inscrever, não é uma promoção compulsória, então eu esperei porque eu queria ficar perto de Campinas. Passou muita gente na minha frente, ou seja; se eu tivesse ido para qualquer lugar, se eu me propusesse a ir para Rosana, Dracena, eu teria me promovido antes, como eu não me propus a ir, eu fiquei esperando uma comarca (Juíza 3).

Essa juíza exprime claramente que a sua opção resultou "ficar para trás", e correlaciona a disponibilidade à mobilidade com o vínculo familiar, especialmente porque seu marido já era juiz titular em Campinas.

Eu conheci meu marido quando eu era substituta. Então, por exemplo, tem uma menina do meu concurso, há seis anos, que ainda é substituta (Juíza 3).

- Porque ela está esperando? (pesquisador)

Porque ela tem quatro filhos, mora em Indaiatuba e está esperando Cabreúva ou Monte Mor. [cidades da região, raio de aproximadamente $50 \mathrm{~km}$.]

- Ela vai ficar até...

Ela não vai se promover enquanto não... ou seja, ela abriu mão da carreira, ela não tem chance, passaram várias pessoas, todas as pessoas dos outros concursos passaram na frente dela.

- Sim, e essas pessoas mesmo que tenham menos tempo na carreira, como já estão progredindo...

Exatamente. Então, por exemplo, eu sou substituta, ela é a mais antiga, ela é a primeira da lista, na medida em que quem está atrás se promove, passa na frente dela, porque aí é outra entrância.

- E ela não pode...

Mesmo se ela se promover para a inicial, a mais antiga na entrância tem preferência sobre ela... 
- Porque não é antiguidade de idade...

De carreira.

- De carreira.

É, na entrância.

A Juíza 3 conheceu o marido quando era substituta, e ele era titular em Campinas. Frente à carreira construída pelo marido, suas opções de mobilidade se restringiram. Como optou pelo marido/família não pôde "correr na carreira", abriu mão e deixou outros passarem na sua frente. O exemplo da amiga torna mais claros o atraso e a desigualdade entre juízes ou juízas, ou entre aqueles com maiores ou menores vínculos familiares, especialmente filhos. Mesmo sendo antiga na carreira, ela não progrediu e não pode concorrer com os juízes mais novos que mudaram de entrância e deixaram de ser substitutos, pois a antiguidade é no tempo de entrância. Um juiz ou juíza recémempossado que progrediu rapidamente para Rosana ou Dracena poderá alcançar Monte Mor antes da juíza antiga que permaneceu em entrância inferior.

Frente ao discurso formal e imparcial de que a progressão na carreira seria por antiguidade, várias entrevistas demonstram um acesso diferencial de acordo com gênero e vínculo familiar. A construção da carreira pelas mulheres estabelece vínculos com família, filhos e tipo de localidade - ou qualidade da comarca que, preferencialmente, impedem-nas de entrar rapidamente na contagem de tempo e progressão.

Ao passo que tem um substituto daqui que é do último concurso que está indo para Mirandópolis, porque ele quer fazer carreira rápido; ele quer ir para São Paulo e ele tem chance e ele topou ir para o fim do mundo. As mulheres não topam, muitas mulheres. Tem outra juíza que é substituta aqui que também chama "X". Ela é substituta mais antiga do que ele e não vai se promover porque está esperando um lugar melhor (Juíza 3). 
Mirandópolis (614 km da capital) que responde por duas penitenciárias $^{5}$ e exige trabalho mais árduo, apareceu como exemplo de não lugar ${ }^{6}$ (Augé, 1994) em mais de uma entrevista. No cálculo das escolhas possíveis, além da distância entram variáveis da qualidade de comarca, tais como: comarca muito atribulada, com muitos processos em atraso, com conflitos intensos, com relações difíceis com funcionários, etc. A qualidade da comarca participa do cálculo do ideal de trabalho jurídico e administrativo. Todavia, como apresentamos no mapa, a Juíza 4 fez uma trajetória até Taubaté, e por meio de permuta mudou para Campinas. Afirma que não queria sair de Taubaté devido ao ambiente de trabalho, à relação com os funcionários e à qualidade de trabalho na vara. Mudar-se para Campinas resultou em dificuldades de adaptação e uma vara "complicada". Segundo ela, o colega agradeceu pela permuta. Abrir mão de Taubaté - ainda que mantivesse a mesma posição na hierarquia funcional - foi necessário para ir ao encontro de marido, família $e$ filhos, $e$ permanecer juíza titular da vara.

Com história também marcada pela dificuldade de locomoção e vontade de estar perto da família em Campinas, a Juíza 8 (estadual, intermediária, 37 anos, recém-casada, sem filhos) contou que foi classificada no fim da lista do concurso, $e$ ainda solteira foi para Ribeirão Preto (224 km de Campinas), permanecendo 5 anos como substituta.

Porque eu tinha pretensão de não fazer a carreira correndo. Porque quando você entra você tem duas opções, ou você faz a carreira correndo e pega qualquer comarca que você vê pela frente, para andar na carreira, ou você faz a carreira

\footnotetext{
${ }^{5}$ Ver Tribunal de Justiça de São Paulo. Disponível em: http://www.tjsp.jus.br/EstruturaOrganizacional/UnidadesAdminCartorarias.aspx, Site SAP. Disponível em: < http://www.sap.sp.gov.br/> . Acesso em: novembro 2013.

${ }^{6}$ Embora não faça parte desta pesquisa, devem existir diversas varas/não lugares no interior do estado. Lugares de passagem que juízes(as) ocupam durante breves períodos de tempo e que, ao não estabelecerem vínculos de permanência e continuidade processual, criam problemas administrativos e jurídicos.
} 
mais devagar e vai escolhendo as comarcas para as quais você quer se promover (Juíza 8).

Disse que poderia ter ido para Paranapanema $(263 \mathrm{~km}$ da capital; $248 \mathrm{~km}$ de Campinas), mas escolheu a proximidade, retardando a carreira.

Retarda, porque a cada promoção que você deixa passar sem se inscrever, vários outros juízes que estão atrás de você vão passando na sua frente. Então, assim, eu, o meu concurso é número 171, hoje eu estou em entrância intermediária, eu tenho um colega do meu concurso que é juiz em Campinas, já de entrância final há vários, há mais de um ano.

E eu fui substituta dele em Campinas, e nós fomos do mesmo concurso. Ele já era titular da vara... na época era final, e eu cheguei a ser substituta e substituí-lo na vara dele. Olha quanto ele passou na carreira na minha frente! Ele foi o segundo colocado no meu concurso, estava no topo da lista, e assim que abriram as promoções ele já correu para se inscrever. Então ele andou muito rápido na carreira (Juíza 8).

Ainda que não tivesse marido ou filhos, essa juíza mostrou a sua necessidade de estar próxima da família. Pode ser a família, ou como diz a Juíza 5:

[...] e eu optei por... não... eu falei: "olha, vou conciliar minha vida com a minha carreira, não vou sair de Campinas". Não me via morando no meio do mato. Eu gosto da cidade, gosto de shopping, gosto de celular, de trânsito...

Enfim: Ribeirão Preto é muito diferente de Paranapanema, ainda que as distâncias sejam parecidas em relação a Campinas. Diferente no tamanho da cidade, na proximidade política com São Paulo, cosmopolitismo, privacidade e anonimato. 
A Juíza 24 (federal, substituta, 32 anos, casada, sem filhos) reside em São Paulo, mas explica a necessidade de locomoção pelo interior que, no caso do TRF-3, estende-se até o estado de Mato Grosso do Sul.

\begin{abstract}
[...] regra, os juízes vão para o interior, porque dificilmente você se titulariza em São Paulo. Eu sou juíza há cinco anos em São Paulo. A titularização deve acontecer, deve chegar na minha possibilidade de titularizar daqui há dois anos; $e$ aí você vai... você está com toda a sua vida organizada aqui, você tem que, eventualmente ir para o interior, com todas as consequências pessoais dessa mudança. [...] essa fase de titularização é uma fase realmente que causa bastante ansiedade em todo mundo, por conta das mudanças na vida pessoal de todos nós.

[...] Em função do deslocamento, de todo o ônus pessoal que é você mudar daqui para, por exemplo, Campo Grande, Pontaporã, Araçatuba, enfim; é uma mudança muito grande na vida. Hoje têm muitos colegas que questionam se vão ou não titularizar, por conta dessas mudanças pessoais (Juíza 24).
\end{abstract}

Do que percebe na profissão e em si mesma, afirma que os homens podem e devem sair, mudar-se e correr atrás das carreiras, embora a carreira ou/e casamento também seja importante para eles. Frente às dificuldades do deslocamento para todos, os homens teriam mais facilidade em ter suas mulheres $e$ filhos os acompanhando. O importante no discurso da Juíza 24 é que a escolha em permanecer substituta traz conflitos para sua autoimagem ao se comparar com os outros profissionais, $e$ frente aos ideais formal e histórico de carreira e progressão masculinos dominantes. Nesse sentido, as juízas fazem referências aos colegas que foram, enquanto elas ficaram, num misto de opção $e$, às vezes, num gosto amargo de ter "perdido o bonde".

Eu deveria ter planos, mas eu não tenho. Uma pessoa normal deveria ter planos, eu tenho que um dia me titularizar, é o que se espera. Mas eu não sou obrigada. Se 
eu quiser ficar para sempre substituta eu vou ficar, porque eu sou inamovível. Ninguém pode me obrigar a me transformar em titular, eu não posso ser processada porque eu não me transformei em titular; mas não é normal. É natural você um dia exercer a titularidade. A peculiaridade que a nossa carreira hoje... eu tenho que ir para o Mato Grosso do Sul, que é um deslocamento grande, sem perspectiva de retorno, e não tenho o apoio familiar nesse sentido. Meu marido não apoia a minha saída, e é uma coisa que eu posso demorar quatro, cinco anos para voltar (Juíza 24).

Embora o gênero seja fundamental nas escolhas da profissão $e$ os vínculos $e$ as restrições familiares sejam mais impositivos para as mulheres do que para os homens, também temos exemplos de homens que abrem mão da carreira.

Quando a Juíza 3 descrevia suas limitações de deslocamento, ela falou de um juiz que optou por Junqueirópolis (644 km da capital, inicial):

[...] diz que não vai sair de lá, adorou. Não tem quase o que fazer lá, gosta daquele estilo de vida interiorano e vai ficar. Tem família perto e resolveu ficar.

- Mas isto é abrir mão da carreira?

É. [...] Quem não abre mão da carreira e quer chegar a desembargador tem que ir para todos os lugares.

E a Juíza 16 (estadual, titular, 38 anos, união estável, sem filhos), que fez carreira rapidamente, também compartilha a existência dessa postura ao compará-la com as suas próprias opções e sua rápida ascensão na carreira.

- [ficar no interior] A não ser que você não queira se promover? (pesquisador).

A não ser que você não queira. Tem colegas meus de concurso que estão no interior até hoje e que não vão sair por várias questões. Porque gostam de morar no interior, porque querem ficar num lugar que tenha só uma vara, que 
eles tenham, que eles sejam juízes eleitorais que tem um acréscimo no salário de três ou quatro mil reais. Então, têm várias. Aí é a opção da pessoa. Eu quis voltar rápido pra São Paulo, então com dois anos e quatro meses eu já estava em São Paulo, até por isso que eu aceitei me promover pra essas cidades distantes. Andradina é a $30 \mathrm{~km}$ do Mato Grosso do Sul, então são 650 km de São Paulo, mas é porque eu não quis escolher algum lugar bom, perto de São Paulo, porque eu queria voltar definitivamente pra São Paulo, logo (Juíza 16).

Finalmente, o Juiz 1 (54 anos, titular, final, casado com professora universitária, com filhos). Embora ele tenha progredido até entrância final, construiu a sua carreira dividindo as oportunidades profissionais com as necessidades da carreira da esposa. Pediu licença durante o período em que ela fez o doutorado no exterior e, acompanhando-a, ficou responsável pelo cuidado dos filhos e da casa.

Afirma dedicação à família, aos filhos e às opções de lazer. Não dá aulas, não participa de comissões no Tribunal, não quer ir para São Paulo, não quer ser assessor de desembargador, da presidência e se considera um excelente juiz. Fala apaixonado da profissão e de sua dedicação. Sonha aposentar e trabalhar como conciliador.

- [...] porque assim... muitas vezes a mulher juíza... ela muitas vezes fica presa, vamos dizer, na sua vara. [...] ela é boa juíza, faz o que precisa, mas até por causa dessas outras atividades ela não é como alguns juízes, por exemplo, que tenho visto que dá aula, que participa de comissão, que está lá no TJ fazendo não sei o que... (pesquisador)

Então você encontrou um juiz mulher aqui. Porque eu também não dou aula, não participo de comissão, não faço nada além; a minha profissão é ser juiz. O que eu faço, a minha atividade é aqui, eu não tenho nenhuma outra. Eu tenho vários colegas que dão aula e que têm outras atividades, eu não faço nada disso não. [...] Eu leio material 
jurídico que é necessário pra resolver os problemas que eu tenho. Compro e leio o que é necessário, e eu procuro aprender com os processos que chegam e me reciclar no contato com os colegas, mas eu tenho... uma boa parte do meu tempo está dedicada a minha família e tal (Juiz 1).

\section{Conclusão}

Embora a carreira na magistratura se defina por critérios institucionais, objetivos $e$ formais de promoção $e$ ascensão profissional, a partir da pesquisa realizada entre juízes(as) no estado de São Paulo, demonstramos neste trabalho que diferentes formas de progressão expressam diferenças e desigualdades de gênero. Essas desigualdades e diferenças têm como fundamento e estão relacionadas às possibilidades de locomoção e mobilidade pelo espaço/território.

Os juízes(as) progridem na carreira por meio da constante mobilidade pelo território, pois para granjear as posições mais elevadas da hierarquia profissional é necessário deslocar-se entre as diferentes entrâncias/comarcas no interior dos estados de São Paulo e no Mato Grosso do Sul. Ainda que essa trajetória se apresente de forma objetiva e pautada por critérios de antiguidade e merecimento, mostramos que o acesso e a disponibilidade à mobilidade são distribuídos de forma diferencial de acordo com gênero.

Se os juízes ou juízas optarem por vínculos familiares e por modo de vida mais sedentário em pequenas cidades do interior do estado, a trajetória profissional e a carreira estarão sujeitas a impedimentos e grandes limitações na sua progressão; ou, pelo menos, não terão a possibilidade de atingir os objetivos na mesma velocidade - "correr na carreira" - daqueles que podem abrir mão, suspender temporariamente, fazer arranjos diferenciados, ou que não têm esses vínculos.

Tais vínculos podem ser traduzidos em um script sexual ou de gênero, pois família, casamento, cuidados e responsabilidades com os filhos restringem preferencialmente as atividades profissionais e a carreira das mulheres. Cuidados e expectativas de 
gênero que limitam as escolhas ao levar em consideração a qualidade do lugar de residência, os ambientes menos hostis de trabalho, a disposição e a disponibilidade dos maridos em acompanhar a trajetória, que resultam em menores rendimentos assim como sub-representação em posições de poder na hierarquia da profissão que são espacialmente distribuídos.

Seja como imposição de gênero, construção de liberdade ou desprendimento de vínculos, os homens apresentam maior facilidade de mobilidade e deslocamento, enquanto algumas mulheres ficam limitadas $e$ não progridem rapidamente às entrâncias finais $e$ aos tribunais de segunda instância. $\mathrm{O}$ deslocamento $e$ a permanência pelo espaço e por lugares são simbólicos e hierárquicos, pois implicam distribuição de poder mediada por construções de gênero.

Os dados apresentados também permitem questionar a segmentação das atividades e habilidades profissionais de acordo com gênero ao compararmos com os(as) advogados(as). Estes últimos definem a carreira e a construção da identidade profissional de forma muito diferente dos juízes(as), ainda que compartilhem a mesma formação acadêmica e um campo de reflexão e de atividade comum. Essa comparação permite afirmar que não é possível analisar as carreiras profissionais em termos de naturalização e constituição de capacidades $e$ habilidades individuais localizadas em gênero. Pois, ao contrário do lugar sedentário dos advogados, a magistratura é marcada pela imposição de mudanças e mobilidade entre diferentes cidades, e o que define a capacidade individual de trabalho e aptidão são as possibilidades de passar por, e ocupar diferentes comarcas/ localidades. Não há um "gueto feminino" em alguma área do direito, pois são independentes de segmentação ou sedimentação de habilidades, seja em vara criminal, de família, comercial ou cível. Não há segmentação de habilidades baseada em desigualdade de gênero na magistratura, mas as formas de estratificação e desigualdade tornam-se subordinadas pelas possibilidades de deslocamento pelo território. São as diferenças de gênero que criam as capacidades diferenciadas de mobilidade 
pelo território e constroem formas de desigualdade, estratificação, poder $e$ hierarquia que independem da segmentação de habilidades na profissão.

De uma perspectiva teórica, procurando ir além das especificidades das magistraturas estadual e federal - e com as limitações de dados apresentados pela pesquisa -, acreditamos que a interconexão entre gênero e capacidade de mobilidade espacial que apresentamos nos permite novas possibilidades de análise de espaços e lugares de gênero. A tese a ser corroborada, refutada ou aprimorada, é a seguinte: para além da magistratura, aqueles que têm mobilidade e deslocamento pelo espaço têm progressão mais rápida e ascendente nas hierarquias, assim como maiores remunerações e prestígio nas diferentes profissões, sendo essa possibilidade e essa capacidade individual distribuídas de forma diferencial e desigual de acordo com gênero.

\section{Referências bibliográficas}

ANLEU, S. R.; MACK, K. Magistrates' everyday work and emotional labour. Journal of Law and Society, vol. 32, $\mathrm{n}^{\circ}$ 4, December 2005, Cardiff University Law School, Blackwell Publishing, Oxford, pp.590-614.

AugÉ, M. Não-lugares: introdução a uma antropologia da supermodernidade. Campinas-SP, Papirus, 1994.

BARBALHO, R. M. A feminização das carreiras jurídicas e seus reflexos no profissionalismo. Tese de doutorado, Programa de Pós-Graduação em Sociologia, UFSCar, São Carlos , 2008.

Bolton, S. C.; Muzio, D. Can't live with 'Em; Can't live without 'Em: gendered segmentation in the legal profession. Sociology 41 (I), London, Thousand Oaks, New Delhi, 2007, pp.47-64. Disponível em: $<$ http://soc.sagepub.com/cgi/content/abstract/41/1/47.

DOI: 10.1177/0038038507072283 > . Acesso em: 15 set 2009 .

Bonelli, M. D. G. Profissionalismo e gênero nas carreiras jurídicas. Universidade Federal de São Carlos. São Carlos. Relatório de Pesquisa, CNPq, 2011. [mimeo] 
BONELl, M. D. G. et al. Profissionalização por gênero em escritórios paulistas de advocacia. Tempo Social, vol. 20, n 1 , junho 2008, São Paulo, USP, FFLCH, pp.265-290.

BouRdieU, P. A dominação masculina. Rio de Janeiro, Bertrand Brasil, 2002 [Tradução de Maria Helena Kuhner].

BRUSCHINI, C.; LOMBARDI, M. R. A bi-polaridade do trabalho feminino no Brasil: o emprego doméstico e as 'novas ocupações'. Cadernos de Pesquisa da Fundação Carlos Chagas, vol.1, no 110, São Paulo, FCC, 2000, pp.67-104.

BUTLER, J. Fundamentos contingentes: o feminismo e a questão do "pósmodernismo". Cadernos Pagu(11), Campinas-SP, Núcleo de Estudos de Gênero-Pagu/Unicamp, 1998, pp.11-42.

CorrêA, M. O sexo da dominação. Novos Estudos CEBRAP 54, São Paulo, $1999 . \quad$ Disponível em: $<$ http://www.pagu.unicamp.br/sites/www.pagu.unicamp.br/files/Bourd ieu.pdf $>$. Acesso em: 17 set 2010.

CostA, R. G. De clonagens e de paternidades: as encruzilhadas do gênero. Cadernos Pagu (11), Campinas-SP, Núcleo de Estudos de Gênero-Pagu/Unicamp, 1998, pp.157-199.

COTTER, D. A. et al. The glass ceiling effect. Social Forces 80(2),University of North Carolina Press, 2001, pp.655-682.

FeUVRE, N. L.; LAPEYERE, N. Les "scripts sexués" de carrière dans le professions juridiques en France. Work \& Society n ${ }^{\circ} 1$, vol. 3, Paris, 2005, pp.101-126.

GORMAN, E. H.; KMEC, J. A. Hierarchical rank and women's organizational mobility: glass ceilings in corporate law firms. American Journal of Sociology, The University of Chicago Press, vol. 114, $\mathrm{n}^{\circ} 5$, March 2009, pp.1428-74.

HAGAN, J.; KAY, F. Even lawyers get the blues: gender, depression, and job satisfaction in legal practice. Law \& Society Review, vol. 41, $\mathrm{n}^{\circ} 1$, 2007, pp.51-78. DOI: 10.1111/J.1540-5893.2007.00291.X

HoCHSCHILD, A. R. The managed heart: commercialization of human feeling. Berkeley; Los Angeles; London: University of California Press, 2003. 
PIERCE, J. L. Gender trials: emotional lives in contemporary law firms. Berkeley; Los Angeles; London: University of California Press, 1995. - Emotional labor among paralegals. The ANNALS of the American Academy of Political and Social Science, 561, January 1999, pp.127-142.

PIERCE, J. L. "Not qualified" or "not committed": a raced and gendered organisational logic in law firms. In: BANAKAR, R.; TRAVERS, M. An introduction to law and social theory. Oxford, Hart Publishing, 2002, pp.155-171.

ScOTT, J. Gênero: uma categoria útil para a análise histórica. Revista de Educação e Realidade (Gênero e Mulheres), vol. 16, n 2, Porto Alegre, 1990, pp.5-22. 